\title{
Nature of, and responses to key sexual and reproductive health challenges for adolescents in urban slums in sub-Saharan Africa: a scoping review
}

\author{
Yohannes Dibaba Wado ${ }^{1 *}$, Martin Bangha', Caroline W. Kabiru ${ }^{1}$ and Garumma T. Feyissa ${ }^{2}$
}

\begin{abstract}
Background: Addressing adolescents' sexual and reproductive health and rights (SRHR) requires an understanding of the socio-cultural and spatial settings within which they live. One setting of particular importance is the informal settlements or 'slums' that are gradually dominating the urban space. We undertook a scoping review and synthesis of existing evidence on adolescent SRHR in slums in sub-Saharan Africa (SSA) focusing on the characteristics and nature of existing evidence.

Methods: The scoping review was conducted based on Arksey and O'Malley framework and in accordance with the guidance on scoping reviews from the Joanna Briggs Institute (JBI) and using PRISMA reporting guidelines for scoping reviews. A comprehensive search was undertaken in PubMed, POPLINE, African Journals Online (AJOL), Bioline International and Google Scholar. The search was confined to studies published in peer reviewed journals and reports published online between January 2000 and May 2019. Studies were included in the review if they addressed SRHR issues among adolescents living in urban slums in SSA.

Results: The review included a total of 54 studies. The majority (79.5\%) of studies were quantitative. The bulk of studies (85.2\%) were observational studies with only eight intervention studies. While half (27) of the studies focused exclusively on adolescents (10-19 years), 12 studies combined adolescents with other young people (1024 years). The studies were skewed towards sexual behavior (44\%) and HIV/AIDS (43\%) with very few studies focusing on other SRHR issues such as contraception, abortion, gender-based violence and sexually transmitted infections (STIs) other than HIV. Most of the studies highlighted the significantly higher risks for poor SRHR outcomes among adolescents in slums as compared to their peers in other settlements.

Conclusion: Young people growing up in slums face tremendous challenges in relation to their SRHR needs resulting in poor outcomes such as early and unintended pregnancy, STIs, and sexual violence. The results of this review point to several potential target areas for programming, policy, and research aimed at improved adolescent SRHR in slums in SSA.
\end{abstract}

Keywords: Slums, SRHR, Adolescents, Scoping review, SSA

* Correspondence: ywado@aphrc.org

'African Population and Health Research Center, APHRC Campus, Manga

Close, P.O. Box 10787-00100, Nairobi, Kenya

Full list of author information is available at the end of the article

C The Author(s). 2020 Open Access This article is licensed under a Creative Commons Attribution 4.0 International License, which permits use, sharing, adaptation, distribution and reproduction in any medium or format, as long as you give appropriate credit to the original author(s) and the source, provide a link to the Creative Commons licence, and indicate if changes were made. The images or other third party material in this article are included in the article's Creative Commons licence, unless indicated otherwise in a credit line to the material. If material is not included in the article's Creative Commons licence and your intended use is not permitted by statutory regulation or exceeds the permitted use, you will need to obtain permission directly from the copyright holder. To view a copy of this licence, visit http://creativecommons.org/licenses/by/4.0/. The Creative Commons Public Domain Dedication waiver (http://creativecommons.org/publicdomain/zero/1.0/) applies to the data made available in this article, unless otherwise stated in a credit line to the data. 


\section{Plain English summary}

Addressing adolescents' sexual and reproductive health and rights (SRHR) requires an understanding of the socio-cultural and spatial settings within which they live. This is critical in the current context where informal settlements or 'slums' are gradually dominating the rapidly expanding urban space. In recognition of the unique challenges, this review highlights existing evidence on adolescent SRHR in slums in sub-Saharan Africa (SSA) with particular attention to available policy responses.

Following standard guidance on scoping reviews from the Joanna Briggs Institute (JBI) and using PRISMA reporting guidelines, data bases such as PubMed, POPLINE, African Journals Online (AJOL), Bioline and Google Scholar were searched. We confined the search to studies published in peer reviewed articles and online reports published between January 2000 and May 2019 and found a total of 54 eligible studies. Half of these studies focused exclusively on adolescents (10-19 years), while the other combined adolescents with other young people.

Results highlight significant risks for poor SRHR outcomes among adolescents in slums as compared to their peers in other settlements. Most studies examined sexual behavior (44\%) and HIV/AIDS (43\%) while SRHR issues such as contraception, abortion and gender-based violence were rarely considered. Overall, the findings show that young people growing up in slums face tremendous challenges in relation to their SRHR needs resulting in poor outcomes such as early and unintended pregnancy, STIs, and sexual violence.

The results point to several potential target areas for programming, policy, and research aimed at improved adolescent SRHR in slums in SSA.

\section{Introduction}

Globally, adolescents (ages 10-19 years) are a significant demographic block. In sub-Saharan Africa (SSA), adolescents account for more than 23\% (or about 250 million) of the total population - a figure that is projected to increase rapidly in near future [1]. Adolescence is associated with physical, emotional and social changes that can increase vulnerability to poor sexual and reproductive health and rights (SRHR) outcomes and other risks associated with behavior change [2, 3].

Adolescents in low- and middle-income countries (LMICs) face tremendous challenges in relation to their SRHR needs. These include lack of access to SRHR information and services; lack of awareness about puberty, sexuality, and basic human rights; poverty; and inequitable gender norms that increase vulnerability to poor SRHR outcomes $[4,5]$. Although adolescent SRHR is gaining global research and programmatic attention $[6$, 7], much of the research and program work overlooks adolescents in the fast growing urban slums in LMICs.
High rates of urbanization in SSA [1] amidst poor economic performance and weak governance has resulted in the growth of informal settlements, commonly referred to as slums. Currently, over half (55\%) of urban dwellers in SSA reside in slums or slum-like environments that are characterized by dire poverty $[8,9]$. Housing structures are temporary and are constructed from mud, iron sheets, cardboard boxes and polythene and plastic sheet tents. They are often located in undesirable parts of the city, such as steep hillsides, riverbanks or industrial areas [10]. The settlements are unregulated and unplanned and are thus characterized by overcrowding, poor sanitation, insecurity and poor access to social amenities. Because of their informal nature, government authorities are reluctant to provide social amenities and services such as schools, roads, and healthcare facilities. As a consequence, residents of slums have poorer health and socio-economic outcomes [10-12].

Urban slum residence creates a confluence of factors that place adolescents at heightened risk of poor SRHR outcomes [9]. For example, studies comparing SRHR outcomes between slum dwellers and non-slum dwellers in Nairobi show that slum residents are at greater risk for HIV infection, risky sexual behavior, early childbearing and maternal mortality [13-16]. Similarly, a study in Lagos, Nigeria shows that maternal mortality rates observed for two slum were higher than the figure estimated for the Lagos State [16].

Recognizing the unique challenges of urban poverty is critical in understanding the drivers of adolescent SRHR outcomes in the slum settings in order to implement effective programs for this critical age group. This review is motivated by the urgent need to understand the drivers of poor SRHR outcomes in slum settlements in SSA and inform prevention efforts. Understanding their SRHR is important for designing programs to improve health, education and employment outcomes among young people that are necessary to achieve the demographic dividend. By providing a comprehensive overview of available research and evidence on adolescent SRHR issues in slums in SSA, this review lay groundwork for a research agenda to explore key knowledge gaps concerning the nature and determinants of SRHR challenges among adolescent slum dwellers, and to inform interventions to address them.

\section{Objective}

The aims of the scoping review were to map and describe available research and evidence on adolescent SRHR in slums in SSA. Specifically, we describe the characteristics, scope, nature of existing evidence and knowledge gaps.

\section{Methods}

We conducted a scoping review method to identify and synthesize evidence on adolescent SRHR in slums in SSA. 
The review was conducted based on Arksey and O'Malley framework [17] and in accordance with the guidance on scoping reviews from the Joanna Briggs Institute (JBI) [18] and using PRISMA reporting guidelines for scoping reviews $[19,20]$. We adopted the five-step method outlined by Arksey and O'Malley (2005): (1) identifying the research question; (2) identifying relevant studies/literature; (3) selecting studies; (4) charting the data; and (5) collating, summarizing, and reporting results.

In line with JBI guidelines, we outlined inclusion criteria for the population, concept, and context as follows:

\section{Population}

The population considered included adolescents/teenagers (ages 10-19 years), young people, general population in the slum areas.

\section{Concept}

Sexual and reproductive health outcomes such as sexual behavior; pregnancy and contraceptive use; HIV/AIDS, gender-based violence (GBV) (physical and sexual violence, intimate partner violence, female genital mutilation and early marriages).

\section{Context}

The review considered the SRHR of adolescents living in urban slums, informal settlements, inner cities or deprived neighborhoods in urban areas in SSA.

\section{Search strategy}

Prior to study selection and data abstraction, a review framework was developed to guide the identification of potentially relevant literature documents. A comprehensive search using databases was undertaken to locate articles published in peer reviewed journals and reports published online. An initial limited search of PubMed was done and text words contained in the titles and abstracts of relevant articles, and the index terms used to describe the articles were used to develop a full search strategy. Following this initial search, we searched the following databases: PubMed, POPLINE, African Journals Online (AJOL) and Bioline International and Google Scholar. The POPLINE website was retired on September 1, 2019 after our search was completed. Different combinations of the following search terms were used: Slums, informal settlements, deprived neighborhoods, inner city, sub-Saharan Africa, teenage/adolescent/ young women/people, young adolescents, SRHR of young people, sexual behavior; pregnancy, contraceptive use; HIV/AIDS, GBV (physical and sexual violence, female genital mutilation and early marriages).

Only articles written in English language published between January 2000 and May 2019 were considered. We also limited our review to studies that included adolescent girls and boys (aged 10-19 years) in their sample.
We also reviewed the bibliographies of studies from the database searches to identify additional articles. Citation searches were also utilized which yielded new studies. We used Google to search for grey literature.

\section{Study selection}

Studies identified from the initial search underwent title and abstract screening. After a full-text review, data were extracted from all selected studies, including the year of publication, country and city of origin, the age and sex category of the study population, the design and type of study, whether it was a single or multi-site study, whether it was a single or multi-topic study, type of SRHR primary outcome. Studies that focused on general urbanization and/or urban poverty and health were reviewed separately and information on the substantive issue was extracted. Included papers were critically appraised using the Preferred Reporting Items for Systematic Reviews and Meta-Analyses-Extension for Scoping Review (PRIMSMA-ScR) guideline [20].

\section{Results}

The initial search yielded a total of 2861 studies. After removing duplicates, 2777 records were left for screening. Upon completion of title and abstract screening, 72 were excluded leaving 133 full-texts deemed potentially relevant for review. Subsequently, 54 documents fulfilled our eligibility criteria and were included in this review (Fig. 1).

The studies identified were reviewed and grouped according to the following categories: sexual behavior; pregnancy and contraceptive use; HIV/AIDs, GBV (physical and sexual violence, female genital mutilation and early marriages). These categories were subsequently used to structure the presentation of results in a systematic manner. It is worth noting that several studies addressed more than one category.

The studies encompassed a variety of study designs including cross-sectional studies, pre-post designs, randomized controlled trials, retrospective and prospective cohort studies and case-control studies (Table 1). We organize our results systematically, beginning with studies on urbanizations, slums and adolescent health in general, then we focus on specific substantive SRHR topics before turning to interventions on adolescent SRHR.

\section{Characteristics of studies on adolescent SRHR in slums}

Among the studies that focused on the substantive topic of adolescent SRHR in slums in SSA, more than half $(n=31 ; 57.4 \%)$ were based on slums in Nairobi, Kenya's capital city (Viwandani, Korogocho and Kibera). Nine (16.7\%) studies covered settlements in South Africa (Cape Town, Johannesburg and Durban), while four (7.4\%) covered Ethiopia (Addis Ababa) and three, Nigeria (Ibadan). Two studies each were based on slums in Uganda (Kampala) and Zimbabwe (Harare) while one 


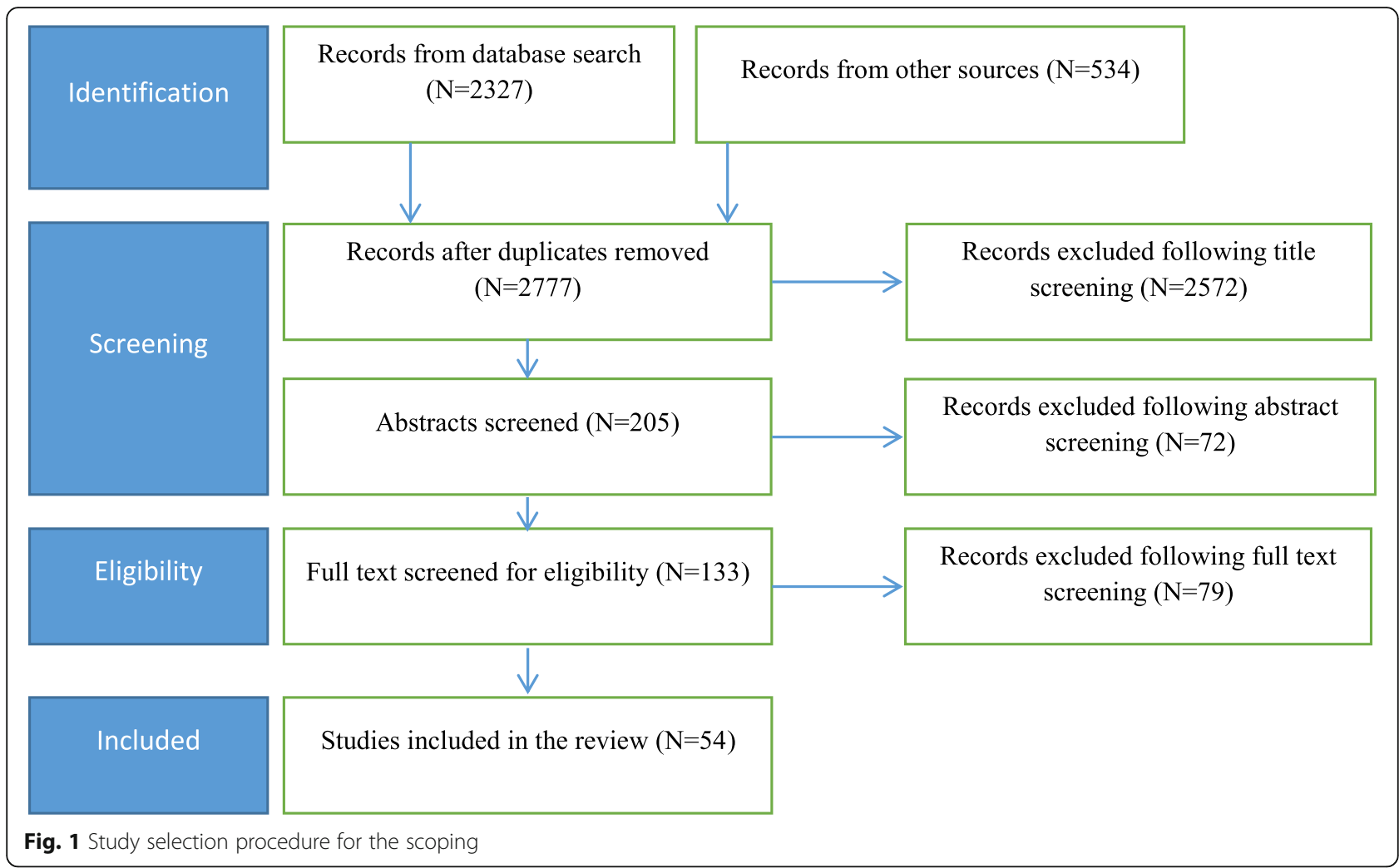

study covered slums in Ghana (Accra), Tanzania (Dar es Salaam) and Malawi (Blantyre).

Majority $41(79.5 \%)$ were quantitative studies while qualitative and mixed methods studies accounted for $13 \%(n=7)$ and $11 \%(n=6)$ respectively. The bulk of studies $(n=46 ; 85.2 \%)$ were observational, crosssectional studies while $14.8 \%(n=8)$ reported on interventions or implementation research.

In terms of study population, many of the studies reviewed did not strictly adhere to the World Health Organization (WHO) definition of adolescents (i.e., those aged 10-19 years). Rather, they combined adolescents with other age groups such as young people (10-24); youths (15-24 years) and women of reproductive age (15-49 years). About half of the studies (27) focused exclusively on adolescents (10-19 years). Twelve studies combined adolescents with other young people (10-24 years), while fifteen treated them as a category in the reproductive age group (15-49 years). For half of the studies, the respondents were girls or young women while the other half combined boys and girls.

It is evident that literature on the adolescent SRHR in slums in SSA has been growing steadily over the last two decades. Dividing the period under consideration into five-year intervals, we noted that $9.3 \%$ were conducted between 2000 and 2004. About $44 \%$ of the studies on adolescent SRHR in the slums in SSA were done between 2010 and 2014. Majority $(74 \%)$ of studies were conducted over the last decade (from 2010 to date).

\section{Adolescent sexual behavior in slums}

This review identified 24 studies (44\%) that investigated sexual behavior among adolescent in the slums of SSA cities. The majority of these studies were quantitative, observational and from Nairobi City slums (Table 2). Most of these studies assessed "risky" sexual behavior, virtually to the exclusion of other sexual behavior among young people.

The sexual risk behaviors examined include early age sexual debut $[11,15,21]$ unprotected sexual intercourse $[15,22,23]$, multiple sexual partnership [11, 15, 24], transactional sex [11, 15, 25] and age-disparate sex [25, 26].

Several studies examined factors that influence adolescent SRHR through the lens of an ecological framework outlining individual, familial/relational, societal and structural level factors. The slum environment in these studies was conceptualized as a mediating variable that intensifies the effect of these factors to cause adverse SRHR outcomes.

Study results showed that risky sexual behavior is strongly shaped by individual and socio-structural forces. The individual factors highlighted include: poor knowledge or access to protection (condoms) [23, 27]. The extent to which adolescents are knowledgeable about protection and have access to them was noted to be a factor determining their use of condoms to prevent against pregnancy, HIV/AIDS and other STIs. Other individual level factors notably associated with risky sexual behavior among adolescents were alcohol, drug and substance use [28-30]. 
Table 1 characteristics of studies included in the review

\begin{tabular}{|c|c|c|}
\hline Area of Focus & Number & $\%$ \\
\hline \multicolumn{3}{|l|}{ Country } \\
\hline Kenya & 31 & $57.4 \%$ \\
\hline South Africa & 9 & $16.7 \%$ \\
\hline Ethiopia & 4 & $7.4 \%$ \\
\hline Nigeria & 3 & $5.4 \%$ \\
\hline Uganda & 2 & $3.7 \%$ \\
\hline Zimbabwe & 2 & $3.7 \%$ \\
\hline Ghana & 1 & $1.9 \%$ \\
\hline Tanzania & 1 & $1.9 \%$ \\
\hline Malawi & 1 & $1.9 \%$ \\
\hline \multicolumn{3}{|l|}{ Design/ Method } \\
\hline Quantitative & 41 & 79.5 \\
\hline Qualitative & 7 & $13.0 \%$ \\
\hline Mixed method & 6 & $11.1 \%$ \\
\hline \multicolumn{3}{|l|}{ Type } \\
\hline Observational & 46 & $85.2 \%$ \\
\hline Intervention/Implementation Research & 8 & $14.8 \%$ \\
\hline \multicolumn{3}{|l|}{ Population } \\
\hline Girls & 26 & 48.1 \\
\hline Boys and Girls & 28 & 51.9 \\
\hline \multicolumn{3}{|l|}{ Age groups } \\
\hline 10-19 & 18 & 33.3 \\
\hline 15-19 & 9 & 16.7 \\
\hline $10-24$ & 12 & 22.2 \\
\hline $15-49$ & 15 & 27.8 \\
\hline \multicolumn{3}{|l|}{ Period } \\
\hline 2000-2004 & 5 & 9.3 \\
\hline 2005-2009 & 9 & 16.7 \\
\hline 2010-2014 & 24 & 44.4 \\
\hline 2015-2019 & 16 & 29.6 \\
\hline Total & 54 & 100 \\
\hline
\end{tabular}

Several studies also reported that young people living in urban slums engage in sexual intercourse much earlier and/or transactional and age disparate sex $[11,14,15,28$, 31]. Adolescents living in slums were found to be more likely to have multiple sexual partners and to report that their most recent sexual intercourse was unprotected than their peers living in wealthier households.

Parental factors such as co-residence and parental control were also highlighted by some studies $[15,25$, 32-34]. These studies show that adolescents living in informal settlements are more likely to be staying on their own or with friends and thus lack formal parental control, which may expose them to riskier behaviors.

Other social factors identified include peer and partner influences that operate in a gendered context and affect adolescent boys and girls differently [15, 23, 25, 28]. Studies suggest that adolescents' relationship dynamics are characterized by unequal decision-making between male and female partners with females having less control over their sexual lives. There is also poor communication about sexual matters by male and female adolescent sexual partners and hence a lack of preparation for or anticipation of intercourse [35].

\section{Adolescent pregnancy}

The review identified 16 studies that investigated adolescent pregnancy. Majority (69\%) of these studies were carried out in Nairobi. Two studies were conducted in Addis Ababa and one each in Kampala, Blantyre, and Johannesburg. The majority of these studies were observational and quantitative in type and design respectively. Only three studies were interventions or implementation research, and five were qualitative or mixed methods in nature.

Most of these studies examined the correlates of adolescent pregnancy in the slums (Table 3). Several studies looked at individual behavior correlates. These were: Low levels of knowledge on the menstruation cycle [15, 24, 32, 36]; low levels of knowledge on contraception or non-use of contraception [37, 38]; early sexual debut; multiple or frequent sexual partnership [11, 24, 36]; transactional and agedisparate sex [30,32] and alcohol and drug use [28, 37, 39].

Other studies looked at socio-ecological factors associated with pregnancy. These were poverty [11, 15, 28, 37]; peer pressure [15, 36, 37]; lack of parental control [15, 33, $39,40]$ and the physical environment $[11,13,39]$.

\section{HIV/AIDS and other STIs}

The review identified 23 studies that investigated HIV/ AIDS in the slums of SSA cities. Some of these studies examined the prevalence and/or incidence of HIV/AIDS in the slums in comparison with other settlements. From these studies (Table 4), the prevalence of HIV was significantly higher in slums than other urban areas and other settlements. For example, in Nairobi the HIV prevalence among young people aged 15-19 years in informal urban settlements (15.2\%) was relatively higher than in formal settlements (11.4\%) [13]. Similarly, across 20 countries in SSA, it was reported that the urban poor have on average 19\% higher odds of being HIV positive than their non-poor urban counterparts of similar background characteristics (age, gender, educational attainment, gender of household head and religion [41].

HIV/AIDS is often transmitted through heterosexual intercourse and most studies in the slum settlements examined sexual behavior patterns that predispose adolescents to HIV infection [11, 13-15, 26, 36, 42]. It is important to note that due to the criminalization of same sex relations in SSA, an accurate estimate of the modes of HIV transmission is difficult. Several 


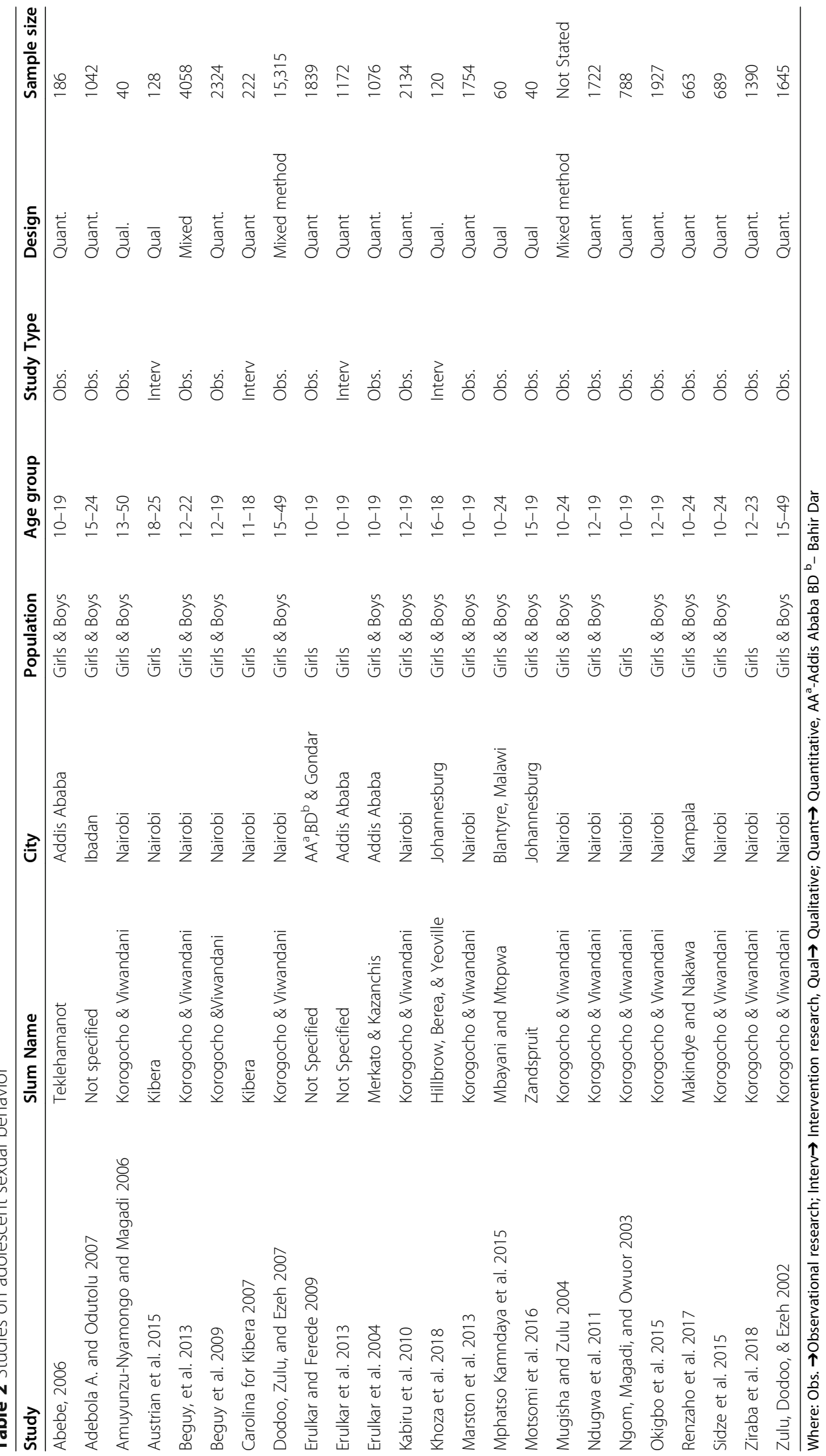




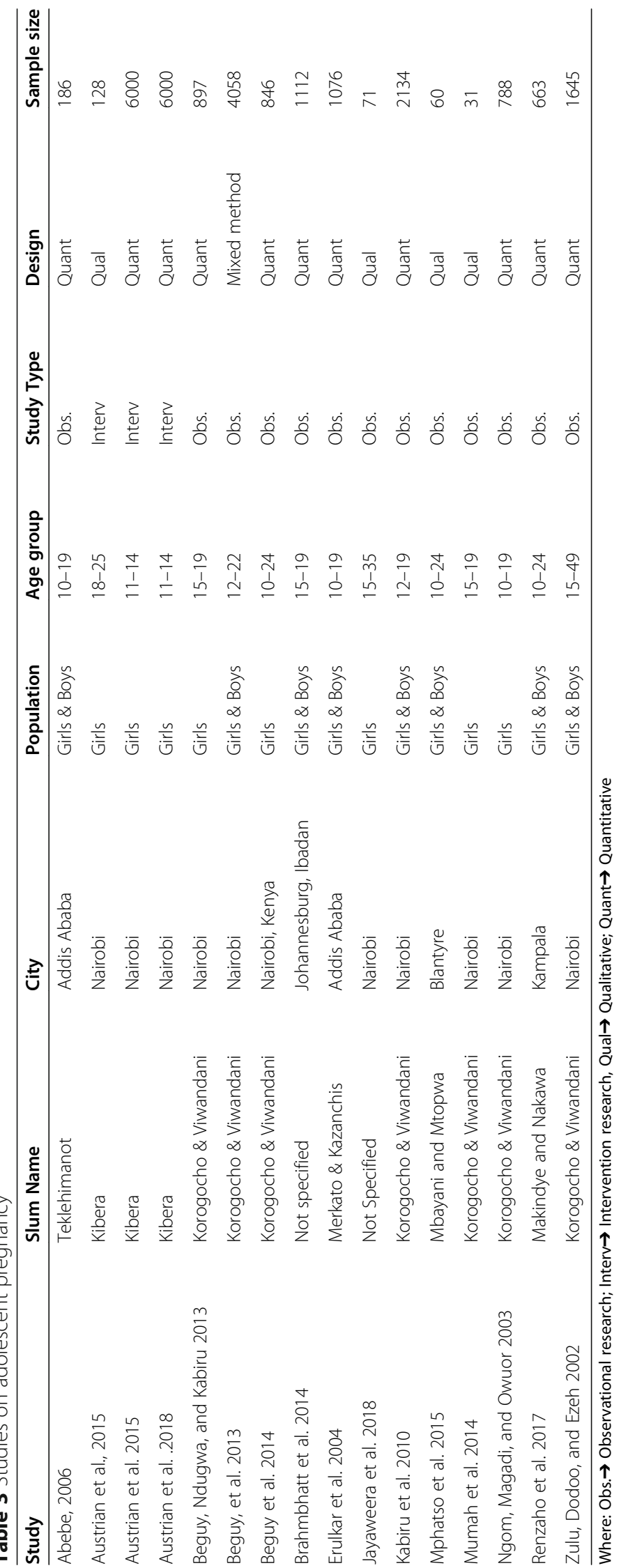




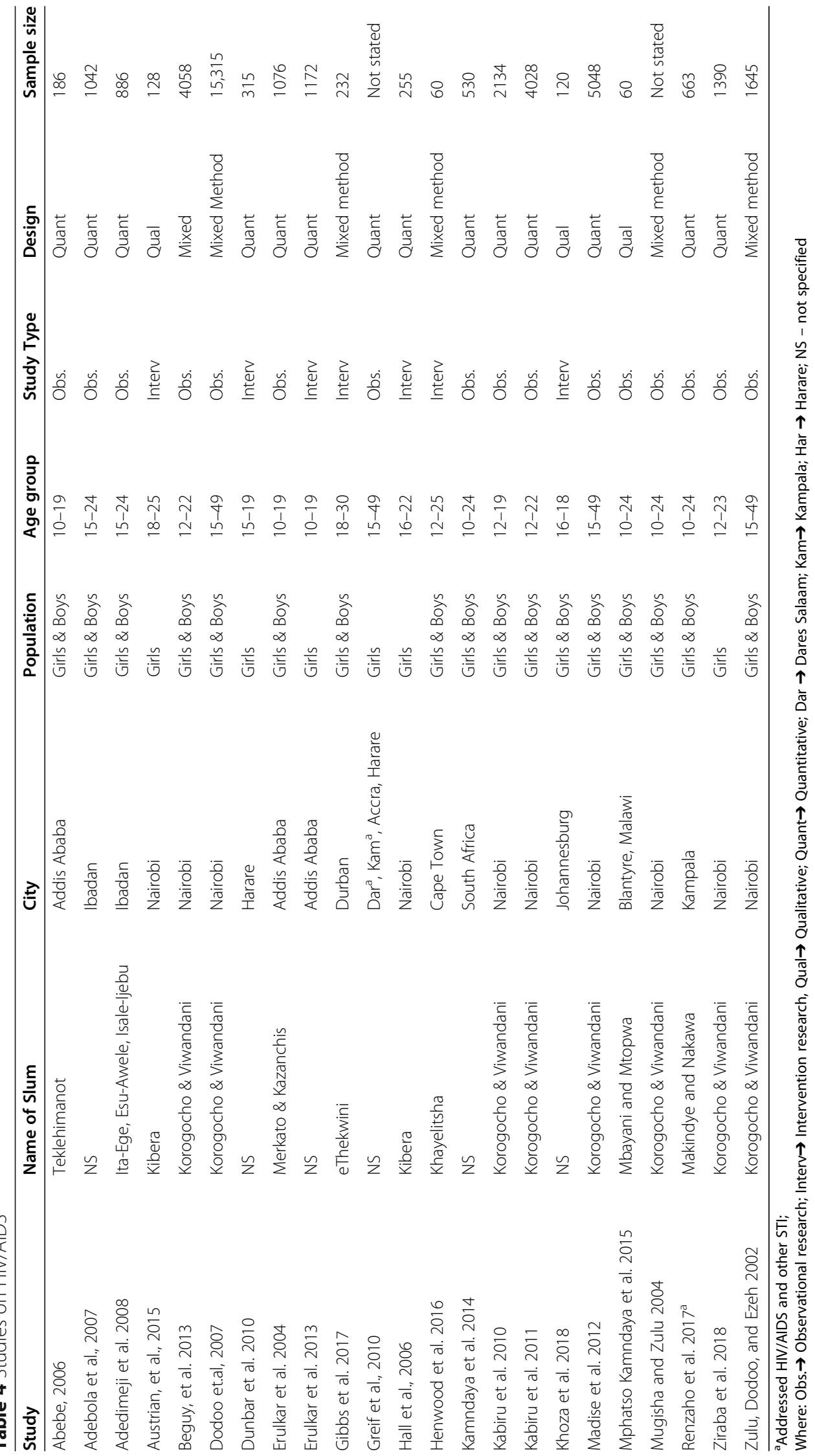


Table 5 Studies on Contraception and Abortion

\begin{tabular}{|c|c|c|c|c|c|c|c|}
\hline Study & Slum Name & City & Population & Age group & Study Type & Design & Sample size \\
\hline & \multicolumn{7}{|c|}{ Contraception/Family planning } \\
\hline Abebe 2006 & Teklehaimanot & Addis Ababa & Girls \& Boys & $10-19$ & Obs. & Quant & 186 \\
\hline Adebola et.al 2007 & Not specified & Ibadan & Girls \& Boys & $15-24$ & Obs. & Quant & 1042 \\
\hline Adedimeji et al. 2008 & Ita-Ege, Esu-Awele, Isale-ljebu & Ibadan & Girls \& Boys & $15-24$ & Obs. & Quant & 886 \\
\hline Austrian et al. 2015 & Kibera & Nairobi & Girls & $11-14$ & Interv & Quant & 6000 \\
\hline Austrian et al. 2018 & Kibera & Nairobi & Girls & $11-14$ & Interv & Quant & 6000 \\
\hline Beguy, et al. 2013 & Korogocho \& Viwandani & Nairobi & Girls \& Boys & $12-22$ & Obs. & Mixed method & 4058 \\
\hline Ochako et al. 2016 & Korogocho \& Viwandani & Nairobi & Girls & $15-49$ & Obs. & Quant & 1873 \\
\hline Renzaho et al. 2017 & Makindye and Nakawa & Kampala & Girls \& Boys & $10-24$ & Obs. & Quant & 663 \\
\hline Sidze et al. 2015 & Korogocho \& Viwandani & Nairobi & Girls \& Boys & $10-24$ & Obs. & Quant & 689 \\
\hline \multirow[t]{2}{*}{ Ziraba et al. 2018} & Korogocho \& Viwandani & Nairobi & Girls & $12-23$ & Obs. & Quant & 1390 \\
\hline & \multicolumn{7}{|l|}{ Abortion } \\
\hline Jayaweera et al. 2018 & Not Specified & Nairobi & Girls & $15-35$ & Obs. & Qual & 71 \\
\hline $\begin{array}{l}\text { Kenya Human Rights } \\
\text { Commission } 2010\end{array}$ & Korogocho & Nairobi & Girls & $15-27$ & Obs. & Mixed method & 65 \\
\hline Renzaho et al. 2017 & Makindye and Nakawa & Kampala & Girls \& Boys & $10-24$ & Obs. & Quant & 663 \\
\hline
\end{tabular}

Where: Obs. $\rightarrow$ Observational research; Interv $\rightarrow$ Intervention research, Qual $\rightarrow$ Qualitative; Quant $\rightarrow$ Quantitative

studies examined how poverty and related economic hardships contribute to risky sexual practices and may increase risk of infection [11, 14, 15, 28, 31, 43].

\section{Contraception and abortion}

About a fifth of the studies examined contraceptive use: three of which investigated patterns of a full range of contraceptives [22, 42, 44], while six studies examined condoms use patterns for dual protection against pregnancies and HIV/AIDS [23, 28, 45-47]. These studies show that adolescents face many barriers in the use of contraceptive methods including lack of access, fear/embarrassment, cost and lack of knowledge. Consequently, the use of contraception among adolescents remains low leading to high levels of unintended pregnancies, unplanned births and unsafe abortion (Table 5).
Only three studies focused on abortion among adolescent girls [38, 42, 48]. These studies underscore unsafe abortion resulting from unintended pregnancies among adolescent girls as a maternal health issue of great concern in most SSA settings where abortion laws are restrictive and safe abortion is largely inaccessible. Therefore, many adolescents in need of pregnancy termination resort to unsafe abortion, which is associated with significant mortality and morbidity risks.

\section{Gender-based violence}

This review identified nine (17\%) studies that investigated GBV among adolescent (Table 6), most of which examined intimate partner physical and sexual

Table 6 Studies on Gender-Based Violence

\begin{tabular}{|c|c|c|c|c|c|c|c|}
\hline Study & Slum name & City & Population & Age group & Study Type & Design & Sample size \\
\hline \multicolumn{8}{|c|}{ General Gender-Based Violence } \\
\hline Abuya et al. 2012 & Not Specified & Nairobi & Girls & $15-19$ & Obs. & Qual & 10 \\
\hline Austrian et al. 2015 & Kibera & Nairobi & Girls & $11-14$ & Interv & Quant & 6000 \\
\hline Austrian et al. 2018 & Kibera & Nairobi & Girls & $11-14$ & Interv & Quant & 6000 \\
\hline Erulkar et al. 2013 & Not Specified & Addis Ababa & Girls & $10-19$ & Interv & Quant & 1172 \\
\hline Gibbs et al. 2017 & eThekwini & Durban & Girls \& Boys & $18-30$ & Interv & Mixed method & 232 \\
\hline Mugisha and Zulu 2004 & Korogocho \& Viwandani & Nairobi & Girls \& Boys & $10-24$ & Obs. & Mixed method & Not stated \\
\hline Renzaho et al. 2017 & Makindye and Nakawa & Kampala & Girls \& Boys & $10-24$ & Obs. & Quant & 663 \\
\hline Swart E. 2012 & Kibera & Nairobi & Girls & $18-30$ & Obs. & Quant & 200 \\
\hline \multicolumn{8}{|c|}{ Female Genital Mutilation } \\
\hline Mudege et al. 2012 & Korogocho\&Viwandani & Nairobi & Girls & $12-24$ & Obs. & Quant & 527 \\
\hline
\end{tabular}

Where: Obs. $\rightarrow$ Observational research; Interv $\rightarrow$ Intervention research, Qual $\rightarrow$ Qualitative; Quant $\rightarrow$ Quantitative 
violence [27, 29, 42, 49-51]. Very few studies focused on child marriage and female genital mutilation [52].

The studies that examined the prevalence, causes and consequences of GBV suggest that it is common among adolescents in slum settlements with adolescent girls more likely to be affected than boys [29, 50-52]. Accordingly, the main driver of GBV may be traditional norms and cultural beliefs that men are more powerful than women and therefore should dominate or control women and their sexuality including sexual intercourse [50-52]. Other correlates include alcohol and drug use [29] and commercial and/or transactional sex [50]. The consequences of GBV highlighted include injury, pain, psychological distress and other mental health illnesses, STIs, including HIV/AIDS, and unintended pregnancy [47, $50,51]$.

\section{Programs and interventions}

The review identified nine interventions targeting adolescent SRHR outcomes in slums in SSA. The interventions encompassed a variety of designs including pre-post quasi- experimental designs, interventions with matched comparison groups, community interventions without comparison or control groups and randomized controlled trials (Table 7). Most of these interventions were conducted in slum areas in East Africa with limited work in Southern Africa and West Africa. Since they targeted adolescents in slum settlement most addressed the socioeconomic correlates of poor adolescent SRHR outcomes by building adolescents' economic and social assets [27, 31, 47, 53-55]. The interventions for economic empowerment of girls included provision of microfinance, financial literacy, cash transfers, and savings programs aimed at reducing adolescents' vulnerability to adverse SRHR outcomes. Some interventions also included the creation of safe spaces where girls could meet and receive training on various issues.

Some interventions focused on comprehensive sexuality education and behavior change communication strategies. These included information provision through mass media, social media, virtual space, social mobilization, advocacy, and through participatory activities $[54,56]$. Others combined sexuality education with microcredit and community mobilization or gender empowerment training combined with life skills and

Table 7 Programs and interventions targeting adolescent SRHR

\begin{tabular}{|c|c|c|c|c|}
\hline Name of the Intervention & City & Target & Study Design & Brief Description \\
\hline $\begin{array}{l}\text { Adolescent Girls Initiative-Kenya } \\
\text { (AGl-K) (Austrian et al. 2015; } \\
\text { Austrian et al.; 2018) }\end{array}$ & Nairobi & $11-14$ years girls & Randomized trial & $\begin{array}{l}\text { Building adolescent girls assets (education, } \\
\text { health, and wealth creation); cash transfer, } \\
\text { savings, financial education, SRHR education } \\
\text { and violence prevention }\end{array}$ \\
\hline $\begin{array}{l}\text { Binti Pamoja Centre (Daughters } \\
\text { United Centre) (Carolina for } \\
\text { Kibera 2007) }\end{array}$ & Nairobi & 11-18 year girls & Community Intervention & $\begin{array}{l}\text { Gender empowerment and creation of safe } \\
\text { spaces for young people in order to 1) reduce } \\
\text { violence, female genital mutilation, sexual } \\
\text { abuse, rape, prostitution, and poverty; and 2) } \\
\text { increase reproductive health knowledge, } \\
\text { financial education, leadership and personal skills }\end{array}$ \\
\hline $\begin{array}{l}\text { BiruhTefta-Bright Future } \\
\text { (Erulkar et al. 2013) }\end{array}$ & Addis Ababa & 10-19 years girls & Quasi-experimental & $\begin{array}{l}\text { Addresses social isolation by building social } \\
\text { capital, literacy, providing information on HIV, } \\
\text { reproductive health and GBV }\end{array}$ \\
\hline CHANGE (Khoza et al. 2018) & Johannesburg & $\begin{array}{l}16-18 \text { girls and } \\
\text { boys }\end{array}$ & $\begin{array}{l}\text { Randomized controlled } \\
\text { trial }\end{array}$ & $\begin{array}{l}\text { Examines the effects of unconditional versus } \\
\text { conditional cash transfers on clinic and school } \\
\text { attendance for HIV prevention }\end{array}$ \\
\hline $\begin{array}{l}\text { TRY-Tap and Reposition Youth } \\
\text { (Hall, Dondo, and Sebstad 2006) }\end{array}$ & Nairobi & $\begin{array}{l}16-22 \text { years } \\
\text { young women }\end{array}$ & $\begin{array}{l}\text { Intervention study with } \\
\text { matched comparison }\end{array}$ & $\begin{array}{l}\text { Improve livelihoods through microfinance, life } \\
\text { skills, financial literacy in order to reduce } \\
\text { vulnerability to adverse SRHR outcomes }\end{array}$ \\
\hline $\begin{array}{l}\text { Stepping Stones (Gibbs et al. } \\
\text { 2017) }\end{array}$ & Durban & $\begin{array}{l}18-30 \text { years } \\
\text { (youth) }\end{array}$ & $\begin{array}{l}\text { Cluster Randomized } \\
\text { Control Trial }\end{array}$ & $\begin{array}{l}\text { Comprehensive sexuality and behavior change } \\
\text { communication (sexual health knowledge, } \\
\text { communication skills, critical reflection and } \\
\text { reduce sexual health risk) }\end{array}$ \\
\hline $\begin{array}{l}\text { Tupange (URHI-Urban } \\
\text { Reproductive Health Initiative } \\
\text { (Speizer et al. 2013) }\end{array}$ & Nairobi & $\begin{array}{l}10-24 \text { years } \\
\text { (young people) }\end{array}$ & $\begin{array}{l}\text { Community Intervention } \\
\text { study }\end{array}$ & $\begin{array}{l}\text { Building capacity of service providers, } \\
\text { contraceptive commodity security, demand-promotion } \\
\text { and advocacy (dispel myth and misconception about } \\
\text { contraceptives) }\end{array}$ \\
\hline $\begin{array}{l}\text { Virtual support group (Khaya } \\
\text { HIV Positive) (Henwood et al. } \\
\text { 2016) }\end{array}$ & Cape Town & $\begin{array}{l}12-25 \text { years } \\
\text { (young people) }\end{array}$ & $\begin{array}{l}\text { Mhealth (social media) } \\
\text { intervention study }\end{array}$ & $\begin{array}{l}\text { Virtual support group. The chat-room used the MXit } \\
\text { social networking platform to provide information on } \\
\text { a youth-friendly HIV services (testing, treatment and } \\
\text { care) and contraception }\end{array}$ \\
\hline
\end{tabular}


financial literacy [27, 47]. The reported outcomes of these interventions included increased knowledge of HIV/AIDS and condom use [27, 57], reduction in the number of sexual partners $[31,55]$ reduced GBV [53, 55, 57] and transactional sexual relationships and improved gender attitudes $[47,57]$.

\section{Discussion}

This scoping review mapped existing evidence on adolescent SRHR in slums in SSA and identified 54 studies published between January 2000 and May 2019. The review showed that adolescents and young people growing up in slums face tremendous challenges in relation to their SRHR needs resulting in poor outcomes such as early pregnancy, STIs, and sexual violence. Of the 54 studies identified, majority were conducted in slum areas in Nairobi, Kenya with very few in other slums areas across SSA.

The scope of the studies is also limited. The literature was skewed towards sexual behavior and HIV/AIDS with very few studies examining other aspects of SRHR such as contraception, abortion, GBV and STIs. The surge in the interest on adolescent sexual behavior is mainly related to the HIV/AIDS prevention programs [58]. This partly explains the narrow focus of these studies on "risky" sexual behavior to the exclusion of other facets of sexuality such as sexual satisfaction, sexual pleasure, eroticism and sexual identity. There is need for studies to explore the whole purview of sexuality such as sexual pleasure and satisfaction, sexual identity, orientation, sexual practices in addition to risky sexual behavior. Unexpectedly, there is minimal research on the utilization of maternal health services by adolescents overall despite the high risk of adolescent mothers to maternal morbidity and mortality due to their unique biological, sociological and economic status [59].

Since most studies were observational, cross-sectional quantitative studies, causal inferences cannot be made. Further, the relative dearth of qualitative studies that interrogate and give deeper insights to the experiences and needs of individuals mean that most studies provide limited data and/or information. As sexuality and other SRHR outcomes are partly driven by cultural norms and beliefs, qualitative studies exploring the roles/influence of contextual characteristics are needed [32,60]. There is also need for studies to go beyond the conventional cross-sectional designs with a view to exploring how sexual behavior, identity, orientation, sexual practices and other SRHR behavior evolve especially in adolescence and younger ages. Studies interrogating puberty, romantic relationships and the effect of gender norms on romantic relationships are also needed. Mixed method designs that incorporate qualitative techniques can be undertaken to provide deeper understanding about these aspects of adolescent SRHR.

Our review highlighted age-overlaps in many of the studies identified. Although adolescent is normally defined as the period between 10 and 19 years [61], many studies identified did not strictly adhere to this definition. Barely half of the studies focused exclusively on adolescents (10-19), while the remaining combined adolescents with other groups namely; young people (1024 years); youths $15-24$ and reproductive age women and men (15-49 years). There is need for more studies on SRHR that focus exclusively on adolescent girls and boys in slums in SSA. Even very critical is the limited number of studies on very young adolescents (10-14), a group with what is called a 'window of opportunity' to address SRHR problems [62] .Early adolescence is a critical time to lay the foundation for healthy and fulfilling sexual and reproductive lives of adolescents. There is need for studies that categorize the adolescent period into early (10-14) and late (15-19) to allow for the comparison of SRHR outcomes and drivers between early versus late adolescence.

The results suggest a general paucity of intervention research that is focused on adolescent SRHR in the slum areas in the SSA. Specifically, intervention studies that allow for the comparison of impacts between early versus late adolescence are lacking. Intervention studies that address differential vulnerability in early and late adolescence among adolescent girls and boys in urban slums also are needed. Understanding what works to improve SRHR in early adolescence will likely lead to healthy trajectories across their life course [46, 63]. Although the identified interventions aimed at addressing the economic and social drivers of adolescent risk to poor SRHR outcomes, not all socio-structural factors highlighted in the review such as parenting were addressed by interventions. There are no interventions that focused on parenting as a key mechanism of socialization of adolescents, yet this was one of the factors that affect their healthy transition into adulthood $[33,34]$. There is therefore need for interventions with and explicit focus on improving parent-child relationships (communication and other dimensions of parenting) in the slums. Finally, comparative studies across sites and SRHR components are lacking. There is a dearth of multi-country or multi-site and multi-theme studies on adolescent SRHR in slums settlement in SSA that can provide generalizable evidence.

Understanding the unique challenges of urban poverty is critical in understanding the drivers of adolescent SRHR outcomes in the slum settings. Rapid urbanization is taking place in SSA in the context of poor economic performance, which presents challenges for adolescents in cities $[8,64]$. There are wide 
disparities in health and socio-economic outcomes between the wealthy and poor urban adolescents: more adolescents in poor urban settings engage in riskier sexual behaviors, have higher HIV infection, experience higher mortality and are more likely to experience violence and drug abuse than their wealthier counterparts $[16,65,66]$. The review focused on several key SRHR issues (sexual behavior, adolescent pregnancy, HIV/AIDS, and GBV among others) but yet has not included studies around puberty, romantic relationships and the effect of gender norms on romantic relationships.

To our knowledge, this is the first scoping review examining adolescent SRHR in urban slums in SSA. Although we used rigorous and transparent methods to ensure a comprehensive search of the literature, it is possible that we did not retrieve all studies in peer-reviewed journals or grey literature. Further, our review only included articles published in English. Nonetheless, the review has yielded important findings on several key SRHR issues that affect adolescents living in resource-limited urban slums in SSA, a region with a high burden of poor SRHR outcomes including early and unintended pregnancy, HIV/AIDS, and GBV.

\section{Conclusion}

The results of this review point to several potential target areas for programming and research aimed at improving adolescents' SRHR. To improve and promote adolescent SRHR, development and well-being, it is important to understand the broader socio-ecological context of slum residence as a risky environment with poor, unhealthy and unsafe living conditions, rather than focusing solely on individual SRHR-related behaviour. Understanding and addressing adolescents' SRHR requires a comprehensive understanding of the contexts that increase their vulnerability to poor outcomes. Interventions that address this risky environment will help adolescents transition into adulthood as a healthy workforce that can help countries in SSA achieve a demographic dividend.

\section{Abbreviations}

AIDS: Acquired immunodeficiency syndrome; GBV: Gender-based violence; HIV : Human immunodeficiency virus; LMICs: Low- and Middle-Income Countries; SRHR: Sexual and Reproductive Health and Rights; SSA: Sub-Saharan Africa; STI: Sexually transmitted infection; UNFPA: United Nations Population Fund; WHO: World Health Organization

\section{Acknowledgments}

The authors gratefully acknowledge the support of Eliud Wekesa in appraising the papers, and Isabella Aboderin in the conceptualization of the project.

\section{Authors' contributions}

YD and MB conceptualized the study, supervised the review process, drafted the manuscript and participated in the interpretation of findings. CK participated in interpretation of findings and in drafting and revising the manuscript. GF contributed to study methodology, interpretation of findings and revising the manuscript. The authors participated in giving final approval of the version to be published.

\section{Funding}

The scoping review was supported by a grant to the African Population and Health Research Center (APHRC) from the David and Lucile Packard Foundation (grant \#2016-6250). Writing time and article processing fees (partial) were supported by a grant from the African Regional Office of the Swedish International Development Cooperation Agency, Sida Contribution No. 12103 for APHRC's challenging the Politics of Social Exclusion project.

\section{Availability of data and materials}

The list of publications used for the scoping review are available in the manuscript and can also be made available upon request.

Ethics approval and consent to participate

Not applicable.

\section{Consent for publication}

Not applicable.

\section{Competing interests}

The authors declare that they have no competing interests.

\section{Author details}

${ }^{1}$ African Population and Health Research Center, APHRC Campus, Manga Close, P.O. Box 10787-00100, Nairobi, Kenya. ${ }^{2}$ Dornsife School of Public Health, Drexel University, Philadelphia, USA.

Received: 22 May 2020 Accepted: 21 September 2020

Published online: 30 September 2020

\section{References}

1. UN. World population prospects 2019:the 2019 Revisision. New York: UN Population Division, Department of Economic and Social Affairs; 2019. https://population.un.org/wpp/Download/Standard/Population.

2. Bearinger LH, Sieving R, Ferguson J, Sharma V. Global perspectives on the sexual and reproductive health of adolescents: patterns, prevention, and potential. Lancet. 2007;369(9568):1220-31.

3. WHO. WHO guidelines on preventing early pregnancy and poor reproductive outcomes among adolescents in developing countries. Geneva: World Health Organization; 2011. https://www.who.int/ immunization/hpv/target/preventing_early_pregnancy_and_poor_ reproductive_outcomes_who_2006.pdf.

4. UNFPA. Adolescent pregnancy: a review of the evidence. New York: United Nations Population Fund; 2013a. https://www.unfpa.org/sites/default/files/ pub-pdf/ADOLESCENT\%2OPREGNANCY_UNFPA.pdf.

5. UNFPA. Motherhood in childhood: facing the challenge of adolescent pregnancy. In: State of the world population 2013. New York: United Nations Popualtion Fund; 2013b.

6. Woog V, Kågesten A. The sexual and reproductive health needs of very young adolescents aged 10-14 in developing countries: what does the evidence show? New York: Guttmacher Institute; 2017. https:/www.guttmacher.org/ report/srh-needs-very-young-adolescents-in-developing-countries.

7. UNFPA. Adolescent sexual and reproductive health. New York: United Nations Population Fund; 2014. https://www.unfpa.org/resources/ adolescent-sexual-and-reproductive-healthNew.

8. UN-HABITAT. World cities report 2016: urbanization and development emerging futures. In: The state of world cities: UN habitat; 2016. https:// unhabitat.org/world-cities-report.

9. Mberu B, Mumah J, Kabiru C, Brinton J. Bringing sexual and reproductive health in the urban contexts to the forefront of the development agenda: the case for prioritizing the urban poor. Matern Child Health J. 2014;18(7): $1572-7$.

10. WHO, UNHSP. Hidden cities: unmasking and overcoming health inequities in urban settings. Geneva: World Health Organization and United nations Human Settlement Program; 2010. https://apps.who.int/iris/handle/1 0665/44439. 
11. Zulu EM, Dodoo FN, Chika-Ezee A. Sexual risk-taking in the slums of Nairobi, Kenya, 1993-8. Popul Stud. 2002;56(3):311-23.

12. Sverdlik L. III-health and poverty: a literature review on health in informal settlements. Environ Urban. 2011;23(1):123-55.

13. Madise NJ, Ziraba AK, Inungu J, Khamadi SA, Ezeh A, Zulu EM, et al. Are slum dwellers at heightened risk of HIV infection than other urban residents? Evidence from population-based HIV prevalence surveys in Kenya. Health \& place. 2012;18(5):1144-52.

14. Dodoo FN, Zulu EM, Ezeh AC. Urban-rural differences in the socioeconomic deprivation--sexual behavior link in Kenya. Soc Sci Med. 2007;64(5):1019-31.

15. Kabiru C, Beguy D, Undie CC, Zulu EM, Ezeh CA. Transition into first sex among adolescents in slum and non-slum communities in Nairobi, Kenya. J Youth Stud. 2010;13(4):453-71.

16. Anastasi E, Ekanem E, Hill O, Adebayo Oluwakemi A, Abayomi O, Bernasconi A. Unmasking inequalities: sub-national maternal and child mortality data from two urban slums in Lagos, Nigeria tells the story. PLoS One. 2017;12(5):e0177190.

17. Arksey H, L OM. Scoping studies: towards a methodological framework. Int J Soc Res Methodol. 2005;8(1):19-32.

18. Peters MD, Godfrey CM, Khalil H, Mclnerney P, Parker D, Soares CB. Guidance for conducting systematic scoping reviews. Int J Evidence-Based Healthcare. 2015;13(3):141-6.

19. Tricco AC, Lillie E, Zarin W, O'Brien KK, Colquhoun H, Levac D, et al. PRISMA extension for scoping reviews (PRISMA-SCR): checklist and explanation. Ann Internal Med. 2018;169(7):467-73.

20. Tricco AC, Lillie E, Zarin W, O'Brien KK, Colquhoun $H$, Levac D, et al. PRISMA extension for scoping reviews (PRISMA-SCR): checklist and explanation. Ann Intern Med. 2018;169(7):467-73.

21. Amuyunzu-Nyamongo MK, Magadi MA. Sexual privacy and early sexual debut in Nairobi informal settlements. Community Work Fam. 2006;9(2):143-58.

22. Beguy D, Mumah J, Wawire S, Muindi K, Gottschalk L, Kabiru C. Status report on the sexual and reproductive health of adolescents living in urban slums in Kenya. In: STEP UP technical working paper. Nairobi: African Population and Health Research Center; 2013.

23. Adedimeji AA, Omololu FO, Odutolu O. HIV risk perception and constraints to protective behaviour among young slum dwellers in Ibadan, Nigeria. J Health Popul Nutr. 2007:25(2):146-57.

24. Erulkar A, Tekle-Ab M, Negussie S, G. T. Adolescent life in low income and slum areas of Addis Ababa, Ethiopia; 2004. Accra Population Council.

25. Ziraba A, Orindi B, Muuo S, Floyd S, Birdthistle IS, J ea M. Understanding HIV risks among adolescent girls and young women in informal settlements of Nairobi, Kenya: lessons for DREAMS. PLoS One. 2018;13(5):e0197479.

26. Renzaho A, Kamara JK, Georgeou N, G K. Sexual, reproductive health needs, and rights of young people in slum areas of Kampala, Uganda: a cross sectional study. PLoS One. 2017;12(1):e0169721.

27. Erulkar A, Ferede A, Girma W, Ambelu W. Evaluation of 'Biruh Tesfa' (bright future) program for vulnerable girls in Ethiopia, 8 (2): 182-92. Vulnerable Children and Youth Studies. 2013;8(2):182-92.

28. Goshu A. A study on contributing factors to adolescents, reproductive behavior in slum areas of Addis Ababa: the case of Teklehaimanot area. Addis Ababa: Addis Ababa University; 2006.

29. Mugisha F, EM Z. The influence of alcohol, drugs and substance abuse on sexual relationships and perception of risk to HIV infection among adolescents in the informal settlements of Nairobi. J Youth Stud. 2004;7(3):279-93.

30. Ndugwa R, Kabiru C, Cleland J, Beguy D, Egondi T, et al. Adolescent problem behavior in Nairobi's informal settlements: applying problem behavior theory in sub-Saharan Africa. Journal of Urban Health: Bulletin of the New York Academy of Medicine. 2011;77(2):S298-317.

31. Khoza N, Stadler J, MacPhail C, Chikandiwa A, Brahmbhatt H, DelanyMoretlwe S. Cash transfer interventions for sexual health: meanings and experiences of adolescent males and females in inner-city Johannesburg. BMC Public Health. 2018;18(1):120

32. Marston M, Beguy B, Kabiru C, Cleland J. Predictors of sexual debut among young adolescents in Nairobi's informal settlements. Int Perspect Sex Reprod Health. 2013;39(1):22-31.

33. Ngom P, Magadi MA, Owuor T. Parental presence and adolescent reproductive health among the Nairobi urban poor. The Journal of adolescent health : official publication of the Society for Adolescent Medicine. 2003:33(5):369-77.

34. Okigbo CC, Kabiru CW, Mumah JN, Mojola SA, Beguy D. Influence of parental factors on adolescents' transition to first sexual intercourse in Nairobi, Kenya: a longitudinal study. Reprod Health. 2015;12:73.
35. Varga CA. How gender roles influence sexual and reproductive health among south African adolescents. Stud Fam Plan. 2004;34(3):160-72.

36. Beguy D, Ndugwa R, C. K. Entry into motherhood among adolescent girls in two informal settlements in Nairobi, Kenya. J Biosoc Sci. 2013;45(6):721-42.

37. Mumah J, Kabiru C, Cea M. Unintended pregnancies in Kenya: a country profile. In: African population and Health Research Center; 2014b.

38. Jayaweera R, Ngui FM, Hall KS, C. G. Women's experiences with unplanned pregnancy and abortion in Kenya: a qualitative study. PLoS One. 13(1):e0191412.

39. Brahmbhatt $H$, Kagesten A, Emerson M, Decker MR, Olumide AO, Ojengbede $\mathrm{O}$, et al. Prevalence and determinants of adolescent pregnancy in urban disadvantaged settings across five cities. The Journal of adolescent health : official publication of the Society for Adolescent Medicine. 2014; 55(6 Suppl):S48-57.

40. Beguy D, Mumah J, L. G. Unintended pregnancies among young women living in urban slums: evidence from a prospective study in Nairobi City, Kenya. PLoS One. 2014;9(7):e101034.

41. Magadi M. The disproportionate high risk of HIV infection among the urban poor in sub-Saharan Africa. AIDS Behav. 2013;17(5):1645-54.

42. Renzaho AM, Kamara JK, Georgeou N, Kamanga G. Sexual, reproductive health needs, and rights of young people in slum areas of Kampala, Uganda: a cross sectional study. PLoS One. 2017;12(1):e0169721.

43. Kamndaya M, Vearey J, Thomas L, Kabiru CW, Kazembe LN. The role of material deprivation and consumerism in the decisions to engage in transactional sex among young people in the urban slums of Blantyre, Malawi. Global public health. 2016;11(3):295-308.

44. Ochako R, Mbondo M, Aloo S, Kaimenyi S, Thompson R, Temmerman M, et al. Barriers to modern contraceptive methods uptake among young women in Kenya: a qualitative study. BMC Public Health. 2015;15(1):118.

45. Sidze E, Elungata'a P, Maina B, Mutua M. Does the quality of parent-child connectedness matter for adolescents' sexual behaviors in Nairobi informal settlements? Arch Sex Behav. 2015;44(3):631-8.

46. Austrian K, Althea D. Barriers and facilitators to health behaviour change and economic activity among slum-dwelling adolescent girls and young women in Nairobi, Kenya: the role of social, health and economic assets. Sex Education. 2015;15(1):64-77.

47. Austrian K, Soler-Hampejsek E, Mumah J, Kangwana B, Wado YD, Abuya B, et al. Adolescent girls initiative-Kenya: midline results report. Nairobi: Population Council; 2018. https://www.popcouncil.org/uploads/pdfs/201 8PGY_AGI-K_MidlineReport.pdf.

48. KHRC. Teenage pregnancy and unsafe abortion: the case of Korogocho slums. Nairobi: The Kenya Human Rights Commission (KHRC); 2010.

49. Gibbs A, Washington L, Willan S, Ntini N, Khumalo T, Mbatha N, et al. The stepping stones and creating futures intervention to prevent intimate partner violence and HIV-risk behaviours in Durban, South Africa: study protocol for a cluster randomized control trial, and baseline characteristics. BMC Public Health. 2017;17(1):336.

50. Abuya B, Onsomu E, Moore D, J. S. A phenomenological study of sexual harassment and violence among girls attending high schools in urban slums, Nairobi, Kenya. J Sch Violence. 2012;11(4):323-44.

51. Swart E. Gender-based violence in a Kenyan slum: creating local, womancentered interventions. J Soc Serv Res. 2012;38(4):427-38,

52. Mudege N, Egondi T, Beguy D, EM Z. The determinants of female circumcision among adolescents from communities that practice female circumcision in two Nairobi informal settlements. Health Sociol Rev. 2012;21 (2):242-50.

53. Kibera Cf: uuangane Tuangaze (Let's Unite and Shed Light). 2006 annual report in: Annual report. Chapel Hill: Carolina for Kibera; 2007.

54. Dunbar MS, Maternowska MC, Kang MS, Laver SM, Mudekunye-Mahaka I, Padian NS. Findings from SHAZI: a feasibility study of a microcredit and lifeskills HIV prevention intervention to reduce risk among adolescent female orphans in Zimbabwe. Journal of prevention \& intervention in the community. 2010;38(2):147-61.

55. Hall J, Dondo A, Sebstad J. Tap and reposition youth (TRY) program: providing social support, savings and microcredit opportunities to adolescent girls at risk for HIV/AIDS in Kenya. New York: Population Council; 2006

56. Henwood R, Gabriela P, Barnett W, Hwang B, Metcalf C, Hacking D, et al. Acceptability and use of a virtual support group for HIV-positive youth in Khayelitsha, Cape Town using the MXit social networking platform. AIDS Care. 2016;28(7):898-903.

57. Jewkes R, Gibbs A, Jama-Shai N, Willan S, Misselhorn A, Mushinga M, et al. Stepping stones and creating futures intervention: shortened interrupted 
time series evaluation of a behavioural and structural health promotion and violence prevention intervention for young people in informal settlements in Durban, South Africa. BMC Public Health. 2014;14:1325.

58. Pettifor A, Bekker LG, Hosek S, DiClemente R, Rosenberg M, et al. Preventing HIV among young people: research priorities for thefuture. J Acquir Immune Defic Syndr. 2013;63(2):S155-60.

59. Banke-Thomas OE, Banke-Thomas AO, Ameh CA. Factors influencing utilisation of maternal health services by adolescent mothers in low-and middle-income countries: a systematic review. BMC pregnancy and childbirth. 2017;17(1):65.

60. Motsomi K, Makanjee C, Basera T, P. N. Factors affecting effective communication about sexual and reproductive health issues between parents and adolescents in Zandspruit informal settlement, Johannesburg, South Africa. The Pan African Medical Journal. 2016;25(October):120.

61. WHO. Health for the world's adolescents. Geneva: World Health Organization; 2014. https://www.who.int/maternal_child_adolescent/topics/ adolescence/second-decade/en/.

62. Woog V, K. A. The sexual and reproductive health needs of very young adolescents aged 10-14 in developing countries: what does the evidence show? New York: Guttmacher Institute; 2017. https://www.guttmacher.org/ report/srh-needs-very-young-adolescents-in-developing-countries.

63. Hindin MJ, Kalamar M, Thompson T, UD U. Interventions to prevent unintended and repeat pregnancy among young people in low- and middle-income countries: a systematic review of the published and gray literature. J Adolesc Health. 2016;59(3):S8-15.

64. Montgomery MR, Hewett PC. Urban poverty and health in developing countries: household and neighborhood effects. Demography. 2005;42(3): 397-425.

65. Speizer IS, Fotso CJ, Davis J, Saad A, Otai J. Timing and circumstances of first sex among female and male youth from select urban areas of Nigeria, Kenya, and Senegal. J Adolesc Health. 2013;53(5):609-16.

66. Thomas L, Vearey J, Mahlangu P. Making a difference to health in slums: an HIV and African perspective. Lancet. 2011:377(9777):1571-2.

\section{Publisher's Note}

Springer Nature remains neutral with regard to jurisdictional claims in published maps and institutional affiliations.

Ready to submit your research? Choose BMC and benefit from:

- fast, convenient online submission

- thorough peer review by experienced researchers in your field

- rapid publication on acceptance

- support for research data, including large and complex data types

- gold Open Access which fosters wider collaboration and increased citations

- maximum visibility for your research: over $100 \mathrm{M}$ website views per year

At $\mathrm{BMC}$, research is always in progress.

Learn more biomedcentral.com/submissions 